University of Nebraska - Lincoln

DigitalCommons@University of Nebraska - Lincoln

3-11-2002

\title{
Transition from negative magnetoresistance behavior to positive behavior in $\mathrm{Co}_{20}\left(\mathrm{Cu}_{1-\mathrm{x}} \mathrm{Ge}_{\mathrm{x}}\right)_{80}$ ribbons
}

J. He

Shenyang National Laboratory for Materials Science and International Centre for Materials Physics, Institute of Metal Research, Chinese Academy of Sciences, Shenyang, People's Republic of China

Z.D. Zhang

Shenyang National Laboratory for Materials Science and International Centre for Materials Physics, Institute of Metal Research, Chinese Academy of Sciences, Shenyang, People's Republic of China

J. Ping Liu

University of Nebraska-Lincoln, pliu@uta.edu

David J. Sellmyer

University of Nebraska-Lincoln, dsellmyer@unl.edu

Follow this and additional works at: https://digitalcommons.unl.edu/physicssellmyer

Part of the Physics Commons

He, J.; Zhang, Z.D.; Liu, J. Ping; and Sellmyer, David J., "Transition from negative magnetoresistance behavior to positive behavior in $\mathrm{Co}_{20}\left(\mathrm{Cu}_{1-\mathrm{x}} \mathrm{Ge}_{\mathrm{x}}\right)_{80}$ ribbons" (2002). David Sellmyer Publications. 44. https://digitalcommons.unl.edu/physicssellmyer/44

This Article is brought to you for free and open access by the Research Papers in Physics and Astronomy at DigitalCommons@University of Nebraska - Lincoln. It has been accepted for inclusion in David Sellmyer Publications by an authorized administrator of DigitalCommons@University of Nebraska - Lincoln. 


\title{
Transition from negative magnetoresistance behavior to positive behavior in $\mathrm{Co}_{20}\left(\mathrm{Cu}_{1-x} \mathrm{Ge}_{x}\right)_{80}$ ribbons
}

\author{
J. $\mathrm{He}^{\mathrm{a})}$ and Z. D. Zhang \\ Shenyang National Laboratory for Materials Science and International Centre for Materials Physics, \\ Institute of Metal Research, Chinese Academy of Sciences, Shenyang 110016, People's Republic of China \\ J. P. Liu ${ }^{\text {b) }}$ and D. J. Sellmyer \\ Department of Physics and Astronomy and Center for Materials Research and Analysis, \\ University of Nebraska, Lincoln, Nebraska 68588-0113
}

(Received 26 October 2001; accepted for publication 9 January 2002)

We report a transition of the giant magnetoresistance (GMR) behavior in nanocrystalline $\mathrm{Co}_{20}\left(\mathrm{Cu}_{1-x} \mathrm{Ge}_{x}\right)_{80}$ ribbons from negative to positive, as the semiconductor $\mathrm{Ge}$ substitutes for the $\mathrm{Cu}$ matrix. The growth of the hexagonal $\mathrm{Co}_{3} \mathrm{Ge}_{2}$ compound leads to a change of the physical origin of the GMR. The normal spin-dependent transport behavior in the $\mathrm{CoCu}$ granular system evolves into Coulomb blockade behavior of electronic tunneling in ribbons with a $\mathrm{Co} / \mathrm{Co}_{3} \mathrm{Ge}_{2} / \mathrm{Co}$ junctionlike configuration. (C) 2002 American Institute of Physics. [DOI: 10.1063/1.1458682]

The (negative) giant magnetoresistance (GMR) effect has been observed in many structures such as antiferromagnetically coupled multiplayers, ${ }^{1,2}$ magnetic granular systems, ${ }^{3,4}$ and tunneling junctions. ${ }^{5}$ Recently, research interest in the GMR effect has turned to hybrid ferromagnetinsulator and ferromagnet-semiconductor structures. ${ }^{6-12}$ The enhancement of insulating characteristics in the nonmagnetic matrix causes the separation of metallic granules by a network of insulating boundaries and the appearance of Coulomb blockade, resulting in the increase of negative GMR. ${ }^{8-11}$ The electronic transport behavior is thought to stem from spin-dependent tunneling.

In addition, several methods such as ion implantation ${ }^{13,14}$ and molecular-beam epitaxy ${ }^{15}$ were used to imbed magnetic Mn particles in semiconductor GaAs or Sb, leading to the behavior of positive magnetoresistance. The strong positive GMR in Mn-implanted GaAs films is correlated with the spacing of magnetic nanoparticles, while in $\mathrm{MnSb}$ films it originates from the Coulomb blockade of electronic tunneling. Here, we report on $\mathrm{Co}_{20}\left(\mathrm{Cu}_{1-x} \mathrm{Ge}_{x}\right)_{80}$ ribbons showing the transition of magnetoresistance from negative to positive with substitution of the metallic matrix $\mathrm{Cu}$ by the semiconductor Ge. The formation of the $\mathrm{Co}_{3} \mathrm{Ge}_{2}$ compound results in the existence of $\mathrm{Co} / \mathrm{Co}_{3} \mathrm{Ge}_{2} / \mathrm{Co}$ junctionlike configurations, which helps to explain the interesting GMR transition.

As-quenched $\mathrm{Co}_{20}\left(\mathrm{Cu}_{1-x} \mathrm{Ge}_{x}\right)_{80}(0 \leqslant x \leqslant 0.1)$ ribbons, $25-30 \mu \mathrm{m}$ thick and $1.2 \mathrm{~mm}$ wide, were fabricated by rapid quenching under argon atmosphere. The ribbons were annealed at $693,723,753$, and $773 \mathrm{~K}$ for $20 \mathrm{~min}$ in $10^{-7}$ Torr. The microstructures were observed using a Philips EM 420 transmission electron microscope (TEM). The magnetization was measured by a superconducting quantum interference

${ }^{a)}$ Also at: Department of Physics and Astronomy and Center for Materials Research and Analysis, University of Nebraska, Lincoln, NE 68588-0113; electronic mail: jun50543@yahoo.com

${ }^{b)}$ Also at: Institute for Micromanufacturing, Louisiana Technical University, Ruston, LA 71272 device (SQUID). Four-probe resistivity measurement was performed by a Lakeshore 7000 system. Typical TEM images of the ribbons are shown in Fig. 1. The phase separation after annealing makes 5-10 $\mathrm{nm}$ magnetic Co particles embed in the large $\mathrm{Cu}$ matrix for pure metallic $\mathrm{Co}_{20} \mathrm{Cu}_{80}$ ribbons [Fig. 1(a)]. As Ge content reaches 0.04-0.06, an elongated structure appears [Fig. 1(b)]. Analysis of x-ray and TEM diffraction patterns shows that the thin slices are the hexago-

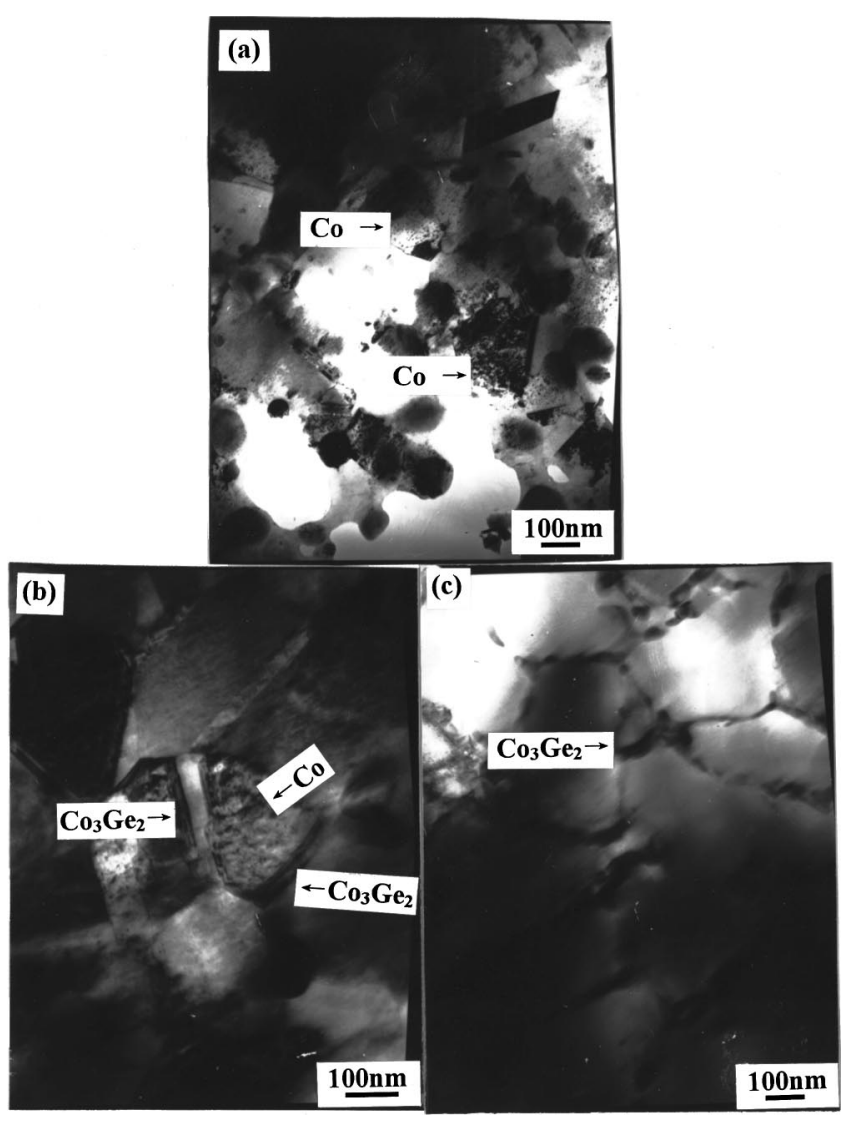

FIG. 1. Bright-field image obtained by transmission electron microscopy (TEM) of $\mathrm{Co}_{20}\left(\mathrm{Cu}_{1-x} \mathrm{Ge}_{x}\right)_{80}$ granular ribbons annealed at $753 \mathrm{~K}$ for $20 \mathrm{~min}$; (a) $x=0$, (b) $x=0.055$, and (c) $x=0.1$. 


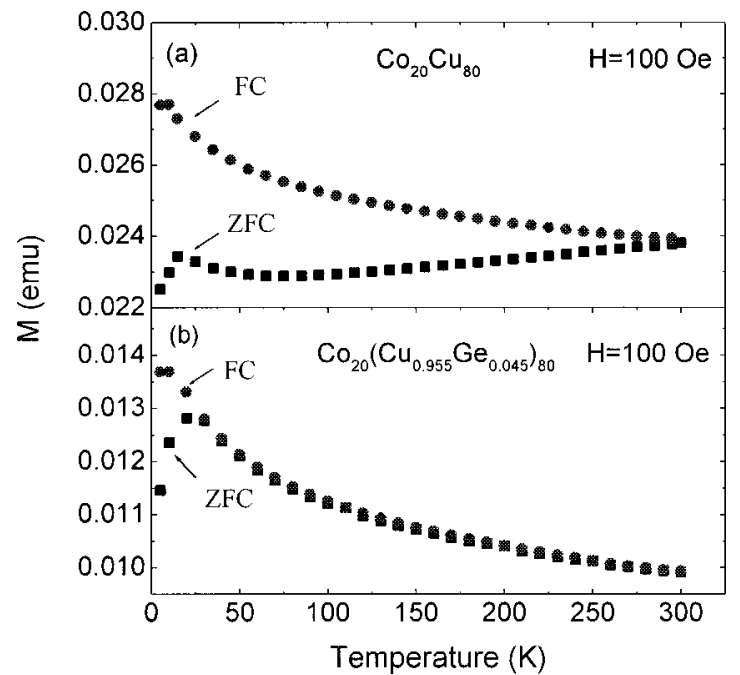

FIG. 2. Magnetization curves after zero-field cooling (ZFC) and field cooling (FC) for (a) $\mathrm{Co}_{20} \mathrm{Cu}_{80}$ and (b) $\mathrm{Co}_{20}\left(\mathrm{Cu}_{0.955} \mathrm{Ge}_{0.045}\right)_{80}$ ribbons annealed at $753 \mathrm{~K}$, respectively. The applied field is $100 \mathrm{Oe}$.

nal $\mathrm{Co}_{3} \mathrm{Ge}_{2}$ compounds. With further increasing the Ge content, as shown in Fig. 1(c), the $\mathrm{Co}_{3} \mathrm{Ge}_{2}$ compound aggregates together in the interface of $\mathrm{Cu}$ clusters to form a network of boundaries. Co nanoparticles nearly disappear in the matrix, indicating that the formation of $\mathrm{Co}_{3} \mathrm{Ge}_{2}$ strongly restrains their growth.

Magnetization versus temperature for zero-field-cooled (ZFC) and field-cooled (FC) curves are shown in Figs. 2(a) and 2(b) for $\mathrm{Co}_{20} \mathrm{Cu}_{80}$ and $\mathrm{Co}_{20}\left(\mathrm{Cu}_{0.955} \mathrm{Ge}_{0.045}\right)_{80}$ annealed ribbons, respectively. The $\mathrm{ZFC}$ and $\mathrm{FC}$ curves of the $\mathrm{Co}_{20} \mathrm{Cu}_{80}$ ribbons are separated at all temperatures. By contrast, the ZFC and ZC curves of the $\mathrm{Co}_{20}\left(\mathrm{Cu}_{0.955} \mathrm{Ge}_{0.045}\right)_{80}$ ribbons nearly overlap above the spin-freezing point. In fact, the effect of the applied field to the magnetic Co moment in the pure $\mathrm{Cu}$ matrix is much stronger than that in the $\mathrm{CuGe}$ matrix due to the decrease of the quantity of magnetic Co particles with $\mathrm{Ge}$ substitution for $\mathrm{Cu}$ [in Fig. (c)]. Thus, the separation of $\mathrm{FC}$ and $\mathrm{ZFC}$ curves for $\mathrm{Co}_{20} \mathrm{Cu}_{80}$ is more obvious than that for $\mathrm{Co}_{20}\left(\mathrm{Cu}_{0.955} \mathrm{Ge}_{0.045}\right)_{80}$, which is in agreement with Ref. 16.

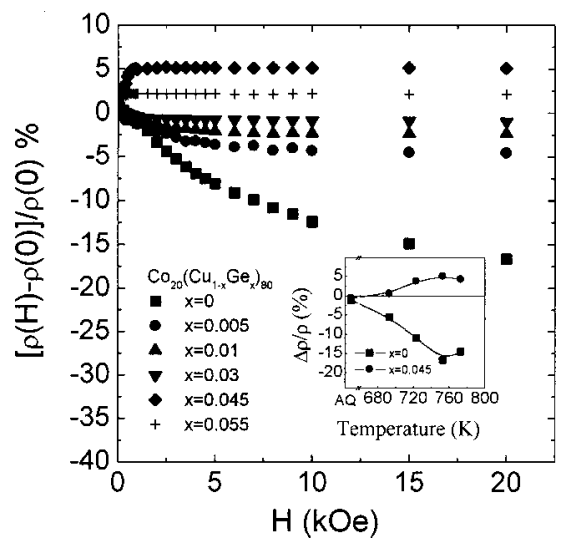

FIG. 3. Transition of magnetoresistance behavior from negative to positive with substitution of $\mathrm{Cu}$ by $\mathrm{Ge}$ for $\mathrm{Co}_{20}\left(\mathrm{Cu}_{1-x} \mathrm{Ge}_{x}\right)_{80}$ granular ribbons annealed at $753 \mathrm{~K}$ for $20 \mathrm{~min}$. The inset shows the evolvement of positive GMR ratio obtained at $H=20 \mathrm{kOe}$ for as-quenched and annealed (at 693, $723,753$, and $773 \mathrm{~K}) \mathrm{Co}_{20}\left(\mathrm{Cu}_{0.955} \mathrm{Ge}_{0.045}\right)_{80}$ ribbons. The negative ratio for $\mathrm{Co}_{20} \mathrm{Cu}_{80}$ ribbons is also shown. The magnetic field is parallel to the longitudinal direction of the ribbons.

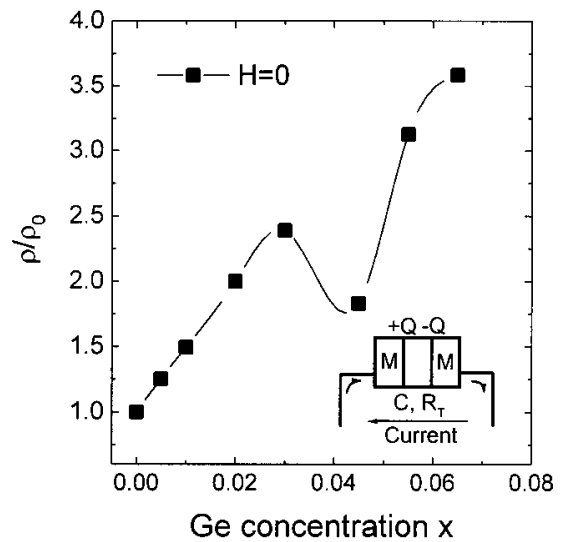

FIG. 4. Ge content dependence of normalized resistivity at zero magnetic field. $\rho_{0}$ denotes the resistivity of Ge-free ribbons. The inset is the sketch of the tunneling process in a single junction, in which $C$ is capacitance, $R_{T}$ is tunneling resistance, and $Q$ is the charge on the pole plate.

As shown in Fig. 3, a clear GMR transition exists with Ge substitution for $\mathrm{Cu}$. The GMR ratio $[\rho(H)-\rho(0)] / \rho(0)$ reaches about $-16 \%$ in the Ge-free ribbons. This negative GMR drops rapidly in the Ge-containing ribbons and the transition from negative to positive takes place as the $\mathrm{Ge}$ content increases to 0.045 . In contrast to the negative GMR effect, the positive GMR effect $(+5 \%)$ saturates at a lower magnetic field $(2.5 \mathrm{kOe})$ with the sensitivity of $10.5 \% / \mathrm{kOe}$. The changes of the GMR ratio with annealing temperature for $\mathrm{Co}_{20} \mathrm{Cu}_{80}$ and $\mathrm{Co}_{20}\left(\mathrm{Cu}_{0.955} \mathrm{Ge}_{0.045}\right)_{80}$ ribbons are exhibited in the inset of Fig. 3. All annealed $\mathrm{Co}_{20}\left(\mathrm{Cu}_{0.955} \mathrm{Ge}_{0.045}\right)_{80}$ ribbons present the positive GMR. Clearly, the electronic transport mechanism in the ribbons has been changed with $\mathrm{Ge}$ substitution for $\mathrm{Cu}$.

The negative GMR effect can be described by the attenuation of spin-dependent scattering due to the alignment of magnetic particles by the external magnetic field. The effect declines with decreasing the amount of the Co particles. However, the existence of $\mathrm{Co}_{3} \mathrm{Ge}_{2}$ compounds in the $\mathrm{Cu}$ matrix changes the conductive homogeneities due to its high resistance. The electronic tunneling should contribute to the electronic transport since many nanosize $\mathrm{Co} / \mathrm{Co}_{3} \mathrm{Ge}_{2} / \mathrm{Co}$ junctionlike configurations are distributed widely [see Fig. 1(b)]. As usual, at low temperatures electronic tunneling in the junctions can be restrained by a large charging energy change at a certain range of charge $Q$, which is called the Coulomb blockade. This effect can enhance the negative GMR effect in a certain condition. ${ }^{9,10}$ However, in $\mathrm{Co}_{20}\left(\mathrm{Cu}_{1-x} \mathrm{Ge}_{x}\right)_{80}$ annealed ribbons, the positive GMR behaviors are observed with increasing $x$. Furthermore, the positive GMR ratio declines to zero with progressive substitution of $\mathrm{Cu}$ by $\mathrm{Ge}$, as shown in Fig. 3. It seems unreasonable to explain this transition by the traditional spindependent tunneling mechanism. Figure 4 shows that the resistivity indeed enhances with Ge substitution when $x$ $<0.03$. As $x$ becomes larger than $0.03, \rho$ suddenly decreases, reminding us of a junction tunneling independent of electronic spins. Basically, a metal-insulator-metal junction with a bias current $I$, as shown in the inset of Fig. 4, can be described by charge $Q$ and the magnitude of tunneling electrons $n$. The electron tunneling leads to the change of static potential: ${ }^{12}$ 


$$
\Delta E^{ \pm}=\frac{Q^{2}}{2 C}-\frac{(Q \mp e)^{2}}{2 C}= \pm \frac{e}{C}\left(Q \mp \frac{e}{2}\right) .
$$

When the temperature is much lower, tunneling can take place only if the energy of the system decreases $(\Delta E>0)$. Namely, the Coulomb blockade appears when charge $Q$ is at a given range: $-0.5 e<Q<0.5 e$. Due to the growth of hexagonal $\mathrm{Co}_{3} \mathrm{Ge}_{2}$ slices, capacitance $C$ of the $\mathrm{Co} / \mathrm{Co}_{3} \mathrm{Ge}_{2} / \mathrm{Co}$ junctions becomes larger so that charge $Q$ on the pole plate increases. When $Q$ surpasses threshold $e / 2$, tunneling occurs in the junctions, resulting in the drop of resistivity, as shown in Fig. 4. The applied magnetic field makes the Coulomb gap $(e / 2 C)$ larger by alignment of Co nanoparticles so that to some extent the junction is restored and the Coulomb blockade effect acts. This seems to cause the positive GMR behavior. When $x>0.06$, more $\mathrm{Co}_{3} \mathrm{Ge}_{2}$ phases form in the ribbons as network-like insulating boundaries while the amount of Co particles decreases in the matrix. On the other hand, the decrease of charging energy $E_{c}=e^{2} / 2 C$, due to the further increase of capacitance $C$, destroys the condition that the charging energy must be much larger than heat fluctuation $k_{B} T$. Thus, it is difficult for the Coulomb blockade to occur when the Ge content is high. Both of these lead to the decrease of the positive GMR effect.

In conclusion, we have presented experimental evidence for the transition of the GMR effect from negative to positive induced by the growth of a $\mathrm{Co}_{3} \mathrm{Ge}_{2}$ phase in the $\mathrm{Co}_{20}\left(\mathrm{Cu}_{1-x} \mathrm{Ge}_{x}\right)_{80}$ ribbons. The interaction between the spin-dependent scattering and the Coulomb blockade of electronic tunneling directly demonstrates the nature of the transition. The interesting GMR transition provides insight into exploring the spin-dependent phenomenon in the semimetal matrix and will be of technological importance in the development of magnetoelectronic research.
This work was supported by the National Natural Science Foundation of China under Grant No. 59725103 and the U.S. NSF under Grant No. INT-9812082. The authors gratefully acknowledge the help of Professor Li-zhi Cheng in the manufacture of the ribbons and Professor Michael O'Shea and Dr. Bao-zhi Cui for the SQUID experiments.

${ }^{1}$ M. N. Baibich, J. M. Broto, A. Fert, F. Nguyen van Dau, F. Petroff, P. Etienne, G. Creuzet, A. Friedrich, and J. Chazelas, Phys. Rev. Lett. 61, 2472 (1988).

${ }^{2}$ S. S. Parkin, N. More, and K. P. Roche, Phys. Rev. Lett. 64, 2304 (1990).

${ }^{3}$ J. Q. Xiao, J. Jiang, and C. L. Chien, Phys. Rev. Lett. 68, 3749 (1992).

${ }^{4}$ S. M. Jordarn, R. Schad, A. M. Keen, M. Bischoff, D. S. Schmool, and H. van Kempen, Phys. Rev. B 59, 7350 (1999).

${ }^{5}$ T. Miyazaki and N. Tezuka, J. Magn. Magn. Mater. 139, L231 (1995).

${ }^{6}$ G. A. Prinz, Science 250, 1092 (1990).

${ }^{7}$ H. Ohno, Science 281, 951 (1998).

${ }^{8}$ H. Akinaga, J. De Boeck, G. Borghs, S. Miyanishi, A. Asmitsu, W. VanRoy, Y. Tomioka, and L. H. Kuo, Appl. Phys. Lett. 72, 3368 (1998).

${ }^{9}$ S. Mitani, S. Takahashi, K. Takanashi, K. Yakushiji, S. Maekawa, and H. Fujimori, Phys. Rev. Lett. 81, 2799 (1998).

${ }^{10}$ S. Mitani, K. Takanashi, and K. Yakushiji, Mater. Sci. Eng., B 84, 120 (2001).

${ }^{11}$ K. Yakushiji, S. Mitani, K. Takanashi, S. Takahashi, S. Maekawa, H. Imamura, and H. Fujimori, Appl. Phys. Lett. 78, 515 (2001).

${ }^{12} \mathrm{H}$. Grabert and M. Devoret, Single Charge Tunneling (Plenum, New York, 1992).

${ }^{13}$ P. J. Wellmann, J. M. Garcia, J. L. Feng, and P. M. Petroff, Appl. Phys. Lett. 73, 3291 (1998).

${ }^{14}$ Sh. U. Yuldashev, Y. Shon, Y. H. Kwon, D. J. Fu, D. Y. Kim, H. J. Kim, and T. W. Kang, J. Appl. Phys. 90, 3004 (2001).

${ }^{15}$ H. Akinaga, M. Mizuguchi, K. Ono, and M. Oshima, Appl. Phys. Lett. 76, 357 (2000).

${ }^{16}$ P. Jena, S. N. Khanna, and B. K. Rao, Cluster and Nanostructure Interfaces (1999). 